\title{
Retraction Note to: Apelin-13 Prevents the Delayed Neuropathy Induced by Tri-ortho-cresyl Phosphate Through Regulation the Autophagy Flux in Hens
}

\author{
Shou-hong Zhou ${ }^{1} \cdot$ Xin-ping Ouyang $^{1} \cdot{\text { Shao-wen } \operatorname{Tian}^{1} \cdot \text { Wei-lan Yin }}^{1} \cdot \mathrm{Bi} \mathrm{Hu}^{1}$
}

Published online: 1 September 2016

(C) Springer Science+Business Media New York 2016

\section{Retraction Note to: Neurochem Res (2015)}

\section{0:2374-2382}

DOI 10.1007/s11064-015-1725-8

The article has been retracted by the Editor-in-Chief due to the fact that Figure 2 was copied from the earlier publication by Song et al., Involvement of autophagy in tri-ortho-cresyl phosphate-induced delayed neuropathy in hens, Neurochem. Int. (2014) 64:1-8 (doi:10.1016/j.neuint.2013.10.017). The figure does not reflect the experiment described. The corresponding author has acknowledged this and agrees to the retraction.

The online version of the original article can be found under doi:10.1007/s11064-015-1725-8.

Shou-hong Zhou

zhoushouhong@126.com

1 Department of Physiology and Institute of Neuroscience, School of Medicine, University of South China,

Hengyang 421001, Hunan, China 